\title{
Clementina Marsico, Nell'officina di Josse Bade: la pubblicazione delle «Elegantie»
}

\section{Filippo Fassina}

\section{Q OpenEdition}

1 Journals

\section{Edizione digitale}

URL: http://journals.openedition.org/studifrancesi/1286

DOI: $10.4000 /$ studifrancesi. 1286

ISSN: 2421-5856

\section{Editore}

Rosenberg \& Sellier

\section{Edizione cartacea}

Data di pubblicazione: 1 décembre 2015

Paginazione: $574-575$

ISSN: 0039-2944

\section{Notizia bibliografica digitale}

Filippo Fassina, «Clementina Marsico, Nell'officina di Josse Bade: la pubblicazione delle «Elegantie»»,

Studi Francesi [Online], 177 (LIX | III) | 2015, online dal 01 décembre 2015, consultato il 08 janvier 2021. URL: http://journals.openedition.org/studifrancesi/1286; DOI: https://doi.org/10.4000/studifrancesi. 1286

Questo documento è stato generato automaticamente il 8 janvier 2021.

\section{(c) $(1) \ominus$}

Studi Francesi è distribuita con Licenza Creative Commons Attribuzione - Non commerciale - Non opere derivate 4.0 Internazionale. 


\title{
Clementina Marsico, Nell'officina di Josse Bade: la pubblicazione delle «Elegantie»
}

\author{
Filippo Fassina
}

\section{NOTIZIA}

CLEMENTINA MARSICO, Nell'officina di Josse Bade: la pubblicazione delle «Elegantie», «Bibliothèque d'Humanisme et Renaissance», LXXVII, 1 (2015), pp. 133-159.

1 L'A. incentra il suo intervento sulle figure di Lorenzo Valla, linguista, filosofo, filologo e teologo di grande fama e di Josse Bade, suo editore e uno dei principali trasmettitori dell'opera di Valla in Europa. Si sofferma, nella prima parte, sul 'fenomeno Valla' evidenziatosi dopo i ricchissimi censimenti dei suoi manoscritti e di numerosi contributi pubblicati in occasione del centenario della nascita dell'erudito italiano, e sull'opera valliana che riscosse il maggior successo a partire dal Quattrocento e per i secoli successivi: le Elegantie lingue latine. Si evidenzia che di tale opera sono state pubblicate numerosissime edizioni e ristampe e che centinaia di studenti europei l'hanno impiegata come manuale di riferimento per l'apprendimento della lingua latina. I recenti censimenti delle stampe del XV e XVI secolo, realizzati da Marielisa Rossi, hanno messo in luce il fatto che molti editori e curatori, soprattutto cinquecenteschi, non si sono limitati a riproporre nelle stampe l'opera intera di Valla, ma l'hanno arricchita con complessi apparati paratestuali, che ne hanno modificato e meglio specificato la lettura. Tra questi, spicca appunto la figura di Josse Bade (1462-1535, noto ai contemporanei come Iodocus Badius Ascensius), che fa delle sue edizioni valliane veri e propri laboratori per l'indagine linguistica e grammaticale, al fine di rendere il testo originale più chiaro e di approfondire gli argomenti più importanti con meticolose ricerche e annotazioni. Lo studioso francese fu uno dei più famosi umanisti della prima metà del Cinquecento e uno dei più importanti editori, critici e commentatori dell'epoca; entrò in contatto diretto con Battista Guarini e 
Filippo Beroaldo il Vecchio e lavorò con celebri stampatori quali Trechsel a Lione e Jean Petit a Parigi e divenne egli stesso stampatore. Commentò autori classici latini e contemporanei, e pubblicò numerosi testi, con l'aggiunta del cosiddetto textus ascensianus, una sintesi di nozioni linguistiche e grammaticali ridotte in versi, in quanto queste erano ritenute più utili della prosa ai fini dell'apprendimento mnemonico della lingua. L'opera di Valla non subì questa riduzione da parte di Bade, ma in alcune edizioni delle Elegantie compaiono, tra i capitoli o tra le epitomi di Bade stesso, versi che sintetizzano concetti particolarmente complessi. La prima edizione dell'opera valliana curata da Bade esce nel 1497 a Parigi; ne seguono altre tre a pochi anni di distanza e se ne aggiungono trentaquattro, fra edizioni e ristampe, entro il 1544.

2 Nel presente studio, l'A. si pone il problema della paternità dei paratesti che affiancano le edizioni di Valla e si chiede, in primo luogo, se possano essere attribuiti con certezza a Bade oppure se siano il risultato di un'ampia collaborazione all'interno dell'officina tipografica e, in secondo luogo, se siano lavori originali o rifacimenti di testi altrui. Soprattutto relativamente alla seconda questione, vengono analizzate le varie fonti delle quali si serve lo stesso Bade e i giudizi che l'erudito francese dà sull'opera e sullo stile di Valla. Viene considerato, poi, l'apparato paratestuale delle edizioni badiane, caratterizzato da un sunto del capitolo e da aggiunta di materiali nuovi, quali precisazioni, confronti, paragoni con altri autori, soprattutto con i 'moderni', novità assoluta per un commento alle Elegantie. Nel complesso, spiccano le modalità di lettura dell'opera valliana da parte di Bade, che dà l'avvio a una meticolosa ricerca, in cui i materiali vengono confrontati e accresciuti, dando vita a un testo che farà scuola e che contribuirà in maniera determinante a diffondere in modo critico e personale il pensiero e le opere di Valla in Europa. 